\title{
A cookbook method for Persuasive Game Design
}

\author{
Panote Siriaraya ${ }^{1}$, Valentijn Visch ${ }^{2}$, Arnold Vermeeren ${ }^{3}$, Michael Bas ${ }^{4}$ \\ 1,2,3. Delft University of Technology, \{P. Siriaraya, V.T.Visch, A.P.O.S. \\ Vermeeren\}@tudelft.nl \\ 4.\&RANJ Serious games design agency, \{bas\}@ranj.com
}

\begin{abstract}
Despite the growing interest in persuasive game design, there have been few methods which cover the complete process of game design that designers could draw upon in their practice. In this paper, the Persuasive Game Design method(PGD) is presented as a non-directive approach for designing persuasive games including a practical hand-out. To better fit with the practical constraints encountered in game design, this method adopts a "cookbook" approach. A set of essential PGD components and tools are provided from which game designers can choose from, given their specific context and resources. Designers first consider the game design steps("dishes") to use in creating their game and in each step, select which components("ingredients") to take into account and tools("utensils") to use. The proposed method, based on our experience as persuasive game researchers and design practitioners, is further refined using feedback from professional game designers. The paper concludes with a case study illustrating how to put the meal into practice. Overall, the method provides a useful contribution to the existing research domain by combining knowledge from game theory, game design and design methodology to create a structured yet flexible approach which covers the complete persuasive game design process for researchers, students and practitioners.
\end{abstract}

Keywords: Persuasive Game Design, Serious Games, Game design, Design method

\section{Introduction}

Game design has been practiced for a long time despite the lack of standard design methods. Or should it be due to the absence of design methods, since rigid design methods might hamper creativity in design. However, in the complex case of persuasive game design, which aims to facilitate the realization of pre-determined user goals going beyond mere entertainment, having a method that can guide the whole design process could be fruitful for both practitioners and researchers alike. A proper method can foster creativity, make the complexity of the design process more manageable and the outcome expectancies more realistic. In this paper, we propose a structural method for designing persuasive games. Our method was developed by using on the one hand the persuasive game design (PGD) model as the theoretical basis [1], and the practical PGD experiences from creative industries and academic design projects on the other hand. According to the PGD model, the core of persuasive game design is to 'transport', c.f. [2], the user's experience from a real world experience towards a more motivational game world experience in order to facilitate the realization of aimed-for transfer effects in the real world [1]. The user experience thus takes a central position in the model since it is the essential factor that has to be influenced in order to realize the aimed-for effects in the game.

The proposed method in this paper aims to cover the complete design process of persuasive games, starting from 'the definition of the desired effect' at the beginning of the process to 'carrying out tests which measure their effectiveness' at the end. Although detailed methods covering specific parts of the design process do exist (e.g. [3, 4] ), only few methods cover the complete process of persuasive game design. Furthermore, a unique feature about the proposed method is that it does not intend to be normative or directive, but instead adopts a "cookbook" approach - c.f. Woolrich [5]. 
We suggest what components should be taken into account ("ingredients") and what tools ("utensils") designers can apply in each step of the design process ("dish"). As with cooking a meal from a recipe, the suggested ingredients minimally needed for a proper dish are proposed and experienced cooks may vary upon them. The utensils which designers choose to use are often selected based on designer expertise, their available resources (e.g. time and money) and the persuasive game context. As such, this approach also serves as an inspiration for ideas in addition to providing a set of example tools and procedures which designers could use to develop their persuasive games.

The paper is structured by first providing a theoretical background of persuasive games and then discussing various methods and models useful in designing persuasive games. Then, the proposed game design recipe concept is described as well as a brief evaluation of the proposed method by professional game designers. Based on this evaluation, we subsequently present the revised and final persuasive game design method. Finally, we discuss a case study to show as an example how the PGD method could be used to support the design of persuasive games.

\section{Theoretical Background}

Games continue to remain a popular pastime in today's society. Games do not only provide entertainment, but also stimulate players to acquire skills that can benefit them outside the experienced world of gameplay. In sports for instance, the physical activity executed during play is beneficial for the physical health of, at least a youthful player (c.f. Strong et al. [6] for a review). Likewise, playing digital action games can be beneficial for the development of the player's cognitive spatial skills [7]. On a more abstract level, being indulged in a fictional story world, often apparent in adventure games, can enhance prosocial skills resulting in an increase in altruistic behavior [8] or change in people's beliefs [9]. In the design of entertainment games, such effects often come secondary, as a spin-off, after the core gameplay experience. These effects which are transferred from interactions in the game world to influence users in the real world, are seen as positive side effects that 'come with the package', just as the negative side effect of decreased empathy seems to come along with violent video games [10].

In serious games however, the position of such effects in the design process is reversed. There, the transfer effects are not considered as an unexpected side effect but as the main aimed-for effect of the design. In other words, people play serious games to obtain these transfer effects. In line with one of the first (educational) serious game theorists Abt [11], serious games "have an explicit and carefully thought-out educational purpose and are not intended to be played primarily for amusement". However, this does not mean that such games are not or should not be entertaining for players. More often, it is exactly this entertainment quality of the game that motivates the player to realize the non-entertaining transfer effects.

The concept of persuasive games is in many ways similar to the concept of serious games. Both have a similar objective in facilitating an aimed for transfer effect which does not have entertainment as the primary goal. While serious games tend to be explicitly designed or thought-out for educational purposes (or learning objectives) [11], persuasive games tend to focus more on the aspect of persuasion, aiming to persuade players to change their beliefs, views or influence their behaviors [12]. Providing a clear distinction between the two could be difficult however, as it is usually dependent upon the developer's (often implicit) intention and the actual context of use. Authors such as Trépanier-Jobin [13] argues that the various cues from the games themselves could help us infer such intentions. For example, the level of realism is one aspect where persuasive games tend to need to be only good enough, serious games need to reach a sufficient level to achieve their learning goals [13]. Apart from this, the characteristics of persuasive game design tend to differ from serious game design. For instance, while in serious game design the mechanics often play the important role, in persuasive game design, user experience often forms the main core. In addition, an aimed-for cognitive or behavioral change-based transfer effects (and its related real world context in which the game operates in) is often at the center of the design process in persuasive game design whereas in serious game design, the transfer effect can be more open-ended. In the next section, the notion of persuasion and persuasive games would be reviewed in more detail.

\subsection{Persuasion and Persuasive games}

The theory of persuasion dates back to the classic Greek philosophy of rhetoric as a communicative means to persuade people. Classical rhetorics are often verbally based [12], and it 
was only with the rise of communication science in the 20th century that rhetorical means are used outside the verbal domain. Initially, these include advertisements that persuade users to consume goods or television entertainment persuading viewers to increase their health literacy. With regard to interactive media such as games, Bogost [12] proclaims the term procedural rhetoric to distinguish interaction-based processes and arguments in games from less-interaction based verbal and visual rhetoric. In his view, in procedural rhetoric "its arguments are made not through the construction of words or images, but through the authorship of rules of behavior, the construction of dynamic models". He believes that it is this interactive aspect found in gameplay that provides users with motivation to change, thus making "persuasive games". Researchers such as Sicart however, argue against the limitation of a rule focused procedural rhetoric, arguing that the meaning of a persuasive game cannot be exclusive to just its rules, and suggests that the element of instrumental play, or the way in which players choose to engage with the existing rules and "play" the game should be taken into account [14]. As such, he proposes that a theory of play could complement the existing notion of procedural rhetoric. Interestingly, De la Hera [15] adds a more persuasive dimension to Bogost's procedural persuasion, which includes narrative persuasion involving components such as a story and characters, and cinematic persuasion involving components such as framing.

Overall, a key difference setting apart persuasive games from entertainment games is that persuasive games are designed with the intention to facilitate the realization of an aimed-for change for the user. These games typically transport the user experience from a real-world experience towards a game-world experience [1], just like entertainment games. However, the crucial difference with entertainment games is that in persuasive games, the gameplay behavior in the game world is designed to facilitate, or 'persuade' the realization of real-world goals. In persuasive game design, the motivations in the experienced game world must be directed by the game designer towards the aimed-for transfer effects. Persuasion in persuasive games can thus be thought of as the designed user motivations in an interactive game world experience that facilitate aimed-for user changes in the real-world. In the PGD model, this change is referred to as a "transfer effect" which is defined as the intended change effect of the user resulting from gameplay. Transfer effects range from changes to a user's attitude about a specific issue (e.g. environmental care [16]) to changes to their behavioral lifestyle (e.g. encourage a healthy lifestyle [17]).

\subsection{Key issues in serious and persuasive games research}

In the last decade, both serious and persuasive games have shown considerable growth and is expected to grow further [18]. In our view however, three fundamental questions still need to be answered to advance the knowledge of research in this domain. These concern a) the validity, b) the mechanism and c) the effective design of serious and persuasive games.

With regard to the validity, much knowledge is still lacking about the proper methods to test and compare real world effects. Recently, a number of studies are emerging to review the effect of such games (such as [19]), as well as proposals calling for more fitting validation methods [20]. Concerning the mechanisms, much is still unknown about how the various game elements work to influence user experience during and after gameplay. Often these elements are developed in unique combinations and tested as a black box (focusing only on the input-output relationship without examining how the underlying mechanisms work in detail), which unfortunately limits the buildup of knowledge on how and when specific game mechanics are effective. This question has inspired research to study the effectiveness of game elements in certain contexts (e.g. [21]) as well as studies which use existing theoretical constructs to help explain how certain game mechanics work [22]. With regards to the design process, several theoretical methods exist and are helpful in guiding designers through specific stages of serious game design. However, there is a lack of a structural approach which can guide designers through the whole process of designing and developing such games. It is this particular topic which this paper attempts to address.

In the following section, the various models and methods which could be useful to the design of persuasive games are discussed. We first examine existing approaches in designing and analyzing games (covering the "game design" dimension of persuasive game design). Afterwards, methods for designing systems aimed at promoting behavior change are covered (covering the "persuasive design" dimension of persuasive games design) followed by existing methods in persuasive game design. 


\subsubsection{Approaches for Game Analysis and Design}

Several theoretical models for analyzing and designing entertainment games have been proposed throughout the past decades. Halfway during the past century, two seminal theorists, Johan Huizinga [23] and Roger Caillois [24] lay the analytical foundation for game research. Huizinga defined games from a player experience-oriented perspective and he proposed a series of game experience characteristics that are typically elicited during game play which can be used to analyze games. About two decades later Caillois [24] further structured the game experiences into two types of play by separating rule-inspired play (e.g. Paidia) from free explorative play (e.g. Ludus) [24] and argues how Paidia is often applied to structure Ludus. More recently, the Mechanics-DynamicsAesthetics framework emerged as the next influential approach to further structure game components [25]. The main advantage of this framework was to expand from the past theories of game play and develop a more formal "vocabulary" to bridge the gap in how games could be analyzed by designers and researchers. Overall, MDA proposes that games could be analyzed by examining the interplay and isolated values of the game's Mechanism, Dynamics and Aesthetics. Later, other researchers such as Juul [26] focused on the interplay between rules and fiction in games and proposed a classical model to help structure games. Expanding upon Huizinga's notion of the magical circle, he proposes that games are an amalgamation of guiding rulesets and fictional worlds which are less coherent and incomplete. Sicard [27] elaborates the concept of game mechanics further by defining them as the "methods invoked by [game] agents, designed for interaction with the game state". In line with Jarvinen [28], Sicard [27] separates rules from mechanics in that rules provide the possible state for interaction whereas mechanics provide the actual interaction.

A key advantage of such theoretical models for designers and researchers is not only to help them better analyze and understand the nature of the games at hand but to also inspire them to reflect upon the various game components and their implications when creating their own games. However, as there is also a need for knowledge and guidelines which could be directly applied to the practice and process of game design, various design methods and suggestions have been proposed based on the previously discussed game components and analytical models. Salen and Zimmerman [29] for instance discussed game design through three different schemas (rules, play and culture). Although part of the knowledge which is offered is theoretical in nature, conceptual guidelines are provided to aid designers in the development and understanding of various game components (feedback design etc.). For digital games, Rollings and Adams [30] provide a more practice-based guideline on the design of various game components (narration etc.) and discuss possible solutions to practical issues such as game balancing. With a more process-oriented goal in mind, Schell's Book of Lenses [3] lists an extended process of game design related theory and provides game design tips and a guiding overview towards good practices in game design.

Overall, much of the existing literature regarding game design provides guidelines which are predominantly conceptual in nature (such as [29], [26] and [31] etc.) and not much is offered about what specific tools and techniques (prototyping techniques etc.) designers could draw upon to address the various design problems in their practice. Schell's book of Lenses is a noteworthy exception, although it is more structured as an anthology of game design processes than as a concise integrative method of persuasive game design. In addition, most of these methods were created to help in the design of entertainment game design. The generalizability of these methods towards persuasive games, which usually aims to have an impact in persuading users to change their behavior in the real world, is unknown.

\subsubsection{Approaches for Behavioral Change Design}

When designing systems aimed at encouraging behavior change, designers could refer to a number of psychology-based analytical models (see Darnton [32] for a review). Most noteworthy are the Reasoned Action Approach [33] and the Health Action Process Approach [34]. Both focus on analyzing the factors (e.g. beliefs, self-efficacy) influencing the gap between user's intention and their resulting behavior. In the context of design, various studies have attempted to link such theoretical models to practical design methods (c.f. [35] for an overview). For instance, Tromp, Hekkert and Verbeek [36] discuss various ways of influencing behavior through design and relate those ways to how people experience their influence. Other approaches have proposed connecting models of behavior change to technology and have examined technology as a medium for change. For instance, Fogg proposed a model for Persuasive design, arguing that the likelihood a user executes a targeted behavior is based on the users' motivation, their ability and the strength of a trigger [37]. He then outlines eight steps which developers can apply in creating and designing 
persuasive technology [38]. To augment the existing persuasive design approach and to provide a tool for design practice, the 'design with intent' method was proposed, grouping the various design techniques for behavior change into "lenses" and proposing different classifications for targeted behaviors and approaches used to influence behavior [39].

Despite the existence of such models and methods, few authors have tried to link persuasive methods directly to game design. Stark's [40] cognitive Behavior Game Design model is a welcome attempt to bridge game design and (learning-based) behavioral change models, but again this model is restricted to transfer effects in the educational domain and relies more on behavioral change models than on game design practice. While the methods offered in the persuasive design literature (c.f. [38], [39]) do provide useful suggestions and tools to help designers understand the intended behavior, user context and situational affordances, it is not clear how they could be integrated and applied to a game design process.

\subsubsection{Approaches for Persuasive Game Design}

Existing models and methods in persuasive game design tend to be mostly theoretical in nature (as discussed in section 2.1). Some of these models offer strategies on different aspects of persuasive game design which designers could find useful in their practice. For instance, Khaled et al. [41] describe how elements such as harmony and group opinion could be used in persuasive game design to persuade players with collectivist cultures. De la Hera [42] has also proposed a theoretical framework to describe three different types of persuasion which can be established through digital games (exocentric persuasion, endocentric persuasion and game-mediated persuasion). Other researchers such as Orji et al. [43] show how different strategies (Self-monitoring, Praise, etc.) could be tailored to specific player groups (Socializers etc.) in persuasive games. At a game theory level, Bogost's persuasive gaming should be mentioned [12]. His intention is not so much to develop a method but merely to legitimate an alternative to the term serious games. In addition, most of the proposed models, strategies and frameworks for persuasive game design tend to focus on specific contexts and application areas. For instance, in the context of pedagogy, the game rhetoric model was proposed by Yusoff et al. [44] and highlights how game rhetoric could be used to implement persuasive learning within games. The Learning Mechanics-Game Mechanics (LM-GM) model proposed by Arnab et al. [45] is also a useful approach for analyzing serious games, in particular regarding the relationship between pedagogical and game elements. Another example is the conceptual model for educational games proposed by Roungas which was later used as the basis for the development of a web-based knowledge management environment to aid in the design of educational games, in particular, to help in the creation of game design documents [46]. Other examples include methods for designing narrative based games in the prison context [47].

While the existing persuasive game models are beneficial in helping inform designers about the different possibilities in persuasive game design, an integrative structured approach is lacking. This could help to guide designers throughout the complete practical process of designing persuasive games. In addition, the existing methods for designing entertainment games might not be easily applied to persuasive game design, as it is often unclear how the real-world persuasion and behavior change aspect could be integrated into the design process. Overall, we see the PGD method presented in this paper as a way to bridge the gap between the various theories and context specific practice methods discussed previously by offering a structured yet flexible generic approach covering the complete process of persuasive game design. Rather than providing a design process which is bound to a specific application domain, we believe that it would be useful to provide a design approach which highlights the available tools and methods which designers could use to answer the necessary questions needed to develop an effective persuasive game in their desired context.

\section{Conceptualizing the Persuasive Game Design Method}

Most of the existing design methods that were discussed above focused either on a specific area within the persuasive game design process (behavioral change design, game mechanic design etc.) or on a specific application domain. To help bridge this gap, we propose a structured approach for designing persuasive games which converts the theoretical Persuasive Game Design model [1] into an integrative design approach. To fit with the practical constraints encountered in game design, a set of commonly used game design components and methods are provided for designers to use in 
constructing their own unique game design approach. This allows designers to tailor their design approach to better suit the context, available resources and their personal design preferences. To provide enough design freedom on one hand and enough practical structure on the other, a "cookbook" metaphor is applied, building on the earlier work of Woolrych et al. [5] who proposed to use this metaphor to communicate methods in the usability research. According to these authors, usability evaluation methods often rely on following prescribed structures, e.g.'recipes', which do not take into account the encompassing context, e.g.'the meal', nor the underlying resources, e.g. 'ingredients'. Based on our previous experience in persuasive game design (authors 2 and 4) and user experience design (author 3) we propose four concepts, which represent the core elements of our design approach: the meal, the dishes, the ingredients and the utensils (See Figure 1).

The Meal: The meal represents the overall game design approach which is crafted by a designer to use in designing their persuasive game. In line with the cooking metaphor, a meal is composed of a number of dishes, each representing major steps in persuasive game design. A carefully designed "meal" is one which, after consideration of the context and available resources, would lead to the successful design of a persuasive game which facilitates the aimed-for real-world transfer effects by enhancing a game-world experience of the end-user.

The Dishes: The typical PGD meal is composed of four dishes. The dishes represent major steps which are commonly used to design a persuasive game. These dishes include:

\section{Dish 1: Defining the transfer effect}

Dish 2: Investigating the user's world

Dish 3: Game Design

\section{Dish 4: Evaluation of effects}

An important aspect of our proposed approach is that to make a proper persuasive game design meal, not all dishes require the same amount of attention or effort. Depending on the task at hand, expertise, time and budget constraints, some designers may choose to focus more of their resources within a particular dish than on others. However, similar to how a meal loses taste when parts of a dish or a whole dish is missing, a persuasive game risks not being able to realize its full potential when parts of the design processes are omitted. In short, the likelihood of success for the overall "meal" decreases with badly cooked dishes.

Exhaustive recipes for each of the dishes are not provided, since they will be highly dependent on the available resources and context of the requested PGD meal at hand. Instead, we provide a list of preferred Ingredients and available Utensils. It should be noted that the ingredients and utensils compiled in this paper for each of the dishes are not conclusive and are provided merely as a guideline: designers are free to add their own ingredients and utensils to the list provided. Overall, it is up to the designer to select which ingredients and utensils to use to "cook" a good dish.

Ingredients - In the cooking metaphor, the ingredients represent the typical components of a dish, such as eggs for a breakfast dish. Although it is advisable to include the ingredients suggested by the recipe to make the dish successful, one may choose to vary the amount of each ingredient and may even leave out certain ingredients or add new ones. However, leaving out an ingredient may come at a cost. In terms of the PGD meal, the ingredients represent the material or components which need to be considered in each of the design stages. For example, when working on defining the transfer effect in dish 1 , one is advised to put in the ingredients (i.e. take into account) the transfer effect change type.

Utensils - Utensils represent the various techniques and tools that designers can use when preparing the ingredients for a dish. As such, utensils are presented as actions which designers can take during each design stage. For instance, the designer can use the utensil "carry out a between subject evaluation study" to examine the ingredient "changes in user behavior" in the dish "Evaluation of effects". 


\subsection{Feedback by experts of the concept of the Persuasive Game design method}

To ensure that the proposed PGD approach would be relevant to the practice of persuasive game design, four experienced game designers from professional serious game agencies in the Netherlands were contacted and asked to review the method. Participants were individually provided with an overview of the PGD approach, its purpose and the relevant background details together with a detailed explanation of the proposed dishes, ingredients and utensils. Open-ended questionnaires were sent to the participants and they were asked to provide written feedback about topics such as the perceived usefulness and relevance of the approach to their design practice, the clarity of the structure, the value of the menu metaphor in communicating the concepts, and suggestions for improvement. By means of personal interviews, the professional game designers were asked to review the existing dishes, ingredients and utensils and provide critical feedback. In addition, they were asked about ingredients and utensils which they used in their practice that were missing in the current PGD method.

Overall, the reviewers felt that the proposed approach and the adopted cooking metaphor was useful in making the previously intuitive design practice more explicit and suggested it could be used in the form of a checklist when designing persuasive games. However, their review also led to some changes to the approach to increase its value to the game design practice. First, the internal coherence between the ingredients and utensils within each dish was improved, with the utensils being described using "actionable verbs" to more clearly represent how various techniques and tools could be used to address the questions encountered in each design step. A detailed description of the available ingredients and utensils in each dish was also provided in a table format (see Appendix A) to improve readability. Furthermore, the ingredients and utensils in the concept design and game design dishes were further revised and extended to better reflect the techniques used in the persuasive game design practice. This was done based on feedback from three separate game designers. The final PGD approach which incorporated these changes are presented in the following section.

\section{The Revised Persuasive Game Design Menu}

This section presents the revised Persuasive Game Design method, providing details about each of the dishes which designers can choose to compose their own PGD meal along with a description of the available ingredients and utensils. A typical PGD meal consists of four dishes, each with their own list of ingredients and utensils. A general overview of the recipe is presented in Figure 1 and the details for each of these dishes are presented below. A comprehensive list of the ingredients and utensil are summarized in the graphical overview cards in Appendix A. 


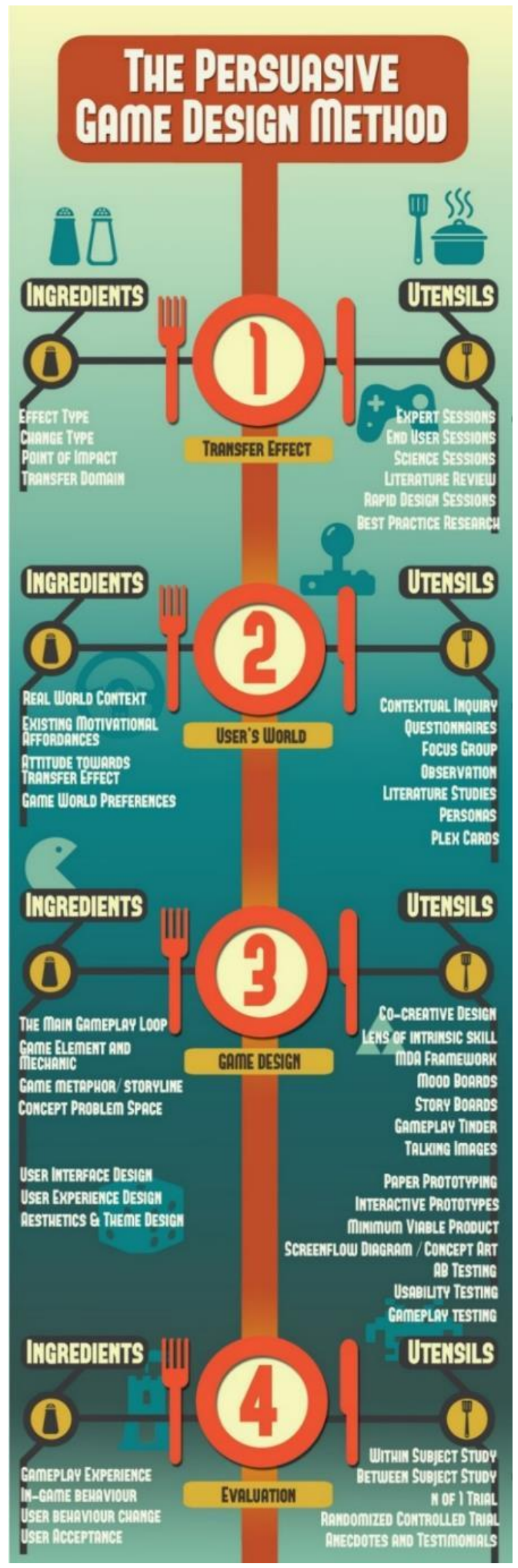

Figure 1: A graphical overview of the (revised) Persuasive Game Design method 


\subsection{Dish 1: Defining the transfer effect}

The first stage of PGD is generally to define the transfer effect that aims to be delivered by the game world experience. It is typically beneficial to clearly define the transfer effect early on in the design process [48] as it will have an influence on the later steps in the design process (such as when selecting which areas to focus on while investigating the user context (dish 2)). In practice however, defining and specifying the transfer effect is often more difficult than it seems. When designing persuasive games in a commercial context for instance, it is easy to confuse the desired goal of the organization with the end user (the employees or clients of the organization etc.). This often results in games which are not effective in engaging end-users, as the expected real-world effects do not align well with their goals and motivations [49]. In some cases, the games are even paid for as a means in itself, as a way of promoting or drawing attention to a certain cause or organization without careful consideration about what specific effects they aim to achieve [50]. In other cases, such as when designing persuasive games for healthcare, it is important to consider the transfer effect carefully in relation to the overall health context to avoid defining an effect which could negatively impacting the health of users.

In defining the transfer effect, the designer could investigate and define which effect type would be appropriate for their persuasive game. This can vary considerably, with examples of games being designed to encourage physical (e.g. increase physical movement to aid in rehabilitation [51]), cognitive or perceptual (e.g. attitude towards environmental care [16]) changes. The change type brought by the transfer effect could also be further specified. The game could help to either reinforce, alter or even encourage players to form new behaviors. In addition, the expected time frame (or point of impact) for forming these behaviors would influence how long users would need to engage with the persuasive game and this should be considered. Transfer effects could be achieved either directly during gameplay (e.g. physical activity in Exergames [52]), shortly after the gameplay (e.g. medicine compliance [53]), or at a much later stage after gameplay (e.g. encouraging users to adopt a healthier lifestyle ( [19]). In addition, designers might also take into account what domain they want the change to take place in, such as in healthcare [19] or business [54]. The transfer effect could be achieved differently depending its application domain. For instance, when looking to increase physical movement to improve well-being for older people, games implemented within a care home in the Dementia healthcare domain could focus on just simple upper body movements [55]. However, to achieve the same transfer effect in the public healthcare context for older adults without dementia and not living in a care home, it is perhaps more optimal to achieve this by stimulating walking behavior in daily life [56].

Various tools, i.e. utensils, could be used to help define the optimal transfer effect. At the early stage of a project, discussions could be carried out, either with domain experts (e.g. researchers) (science sessions) or practitioner experts (e.g. medical practitioners) (expert sessions) to understand more about what transfer effect is desired. For instance, in [56] in-depth interviews and workshops carried out with caretakers helped identify difficulties in verbal communication between caretakers and the older patients as one of the problems in Dementia care. Therefore, a persuasive game was designed with the aim of helping caregivers to enhance their understanding of the patient in a fun way. Similarly, these discussions could be carried out with end users themselves in the form of end user sessions. Another approach common in academic game design projects is to investigate scientific literature on relevant topics to gain more insight into what transfer effects could best benefit the desired population. An often overlooked but effective way to help define the transfer effect is to deconstruct effective methods already used for the same purpose in the real world environment and frame that within the transfer goal (i.e. best practice research). In commercial serious game design practice, a more common approach in identifying the desired transfer effect is by organizing rapid design sessions with stakeholders and clients. To help stakeholders frame their desired business goals within the scope of a gamification project, these sessions are carried out at an early stage to align the interests of all the stakeholders involved and form an accurate transfer goal.

\subsection{Dish 2: Investigating the user's world}

As Persuasive Games intend to have an effect outside the game world, it is important for a designer to get acquainted with the real-world context in which these effects are intended to be realized [49]. When viewed from a design perspective, persuasive games are in essence, user experience design projects [57]. In order to fit the design to the preferences, needs and capabilities of the specific user, such projects typically start from learning more about the context which one 
designs for, such as the user's characteristics, values and needs (e.g. [58]). Overall, two extreme positions can be identified when designing persuasive games: The designer could integrate the game in an existing real-world context (real-world tasks would be reflected through game world activities (such as in [55])) or could design games that are aimed at affecting the user inside the game world) are completely contained in the game world (such as in [16]). In the latter cases, after having been immersed in the game, the player returns to the real world where the transfer effect should take place, for instance by executing the skills learned during the gameplay.

A number of factors regarding the user's world could be investigated (See Appendix A). Designers might wish to examine the real world context in which the game would take place. For instance, when designing a persuasive game which is used as part of a workplace context, the designer might choose to examine the user's current activities, relationships and daily rituals within that workplace (as in [59]). Other factors include the user's existing motivational affordance. Designers could examine how the user's needs, values, beliefs and concerns relate to the desired transfer effect. Some users might prefer games which gratify their need for achievement while others might prefer games which appeal more to their social needs. In addition, designers could look into the user's current attitudes towards the transfer effect such as their personality traits and characteristics. This could be particularly important for instance when designing mental healthcare games. For example, when designing games for clients with ADHD, designers would need to consider that their users could likely have impairments towards their working memory and inhibition system and could have a preference for immediate rewards [60]. Finally, designers could look into the user's game world preferences and examine their desired game world experiences. In the simplest form, designers could examine which type of games the particular user group is responsive to. For instance, when designing for older people a designer might study and be inspired by the motivations of this target group for puzzle and memory games, and might consequently use game elements in her design or target at similar game experiences [61].

For the utensils in this dish, a number of methods and techniques drawn from the field of research and design could be used to learn more about the user's real world. Questionnaires or focus group discussions can be used to ask users to express their opinions, experiences or preferences about a specific situation. Similar methods could be used to gather information from experts, especially in cases where it is difficult to carry out investigations with end-users themselves (such as with people with dementia). This is preferably done in combination with observations. Where observations can help designers empathize with the users by allowing them to observe all kinds of actions and responses first-hand, experts can help provide an overview and give more generalizable information based on their extensive experience engaging with large groups of users and their knowledge about related theories and models. Contextual inquiry, a method used in design to gain in-depth understanding about the users' context by observing and interviewing them while they work in their own environment could also be applied to persuasive game design.

To investigate the user's game world interests, PLEX cards (Playful experience cards) could be particularly useful in representing the possible playful experiences which might appeal to the user [62]. Another method useful to help translate the findings about the user's real world context for the game design team is the creation of personas. Personas are representations of users, carefully crafted based on the information collected using the other methods, and presented in such a way, that other people in the design team can easily empathize with them.

\subsection{Dish 3: Persuasive Game Design}

The third dish represents the process of game design. This process generally consists of two key parts. In the first part, different concepts and game ideas are explored, evaluated and then refined into an initial game concept. In the second part, the persuasive game is created based on the selected game concept. In this part, the various components of the persuasive game (the narrative, gameplay experience and user stories etc.) are designed, prototyped, tested and refined. In projects which involve digital persuasive games, this is usually done in conjunction with the technical development of the game as part of an iterative, agile design and development cycle [63].

\subsubsection{Dish 3.1 Game Concept design}

In general, the conceptualization of a persuasive game follows two principles in succession, starting with the divergence and followed by the convergence of ideas. The objective of the divergence stage is to explore possible persuasive game ideas and concepts which can be achieved by methods such as brainstorming. The divergence stage is followed by the convergence stage where 
the concepts are evaluated and ranked based on how well they fit with the aimed-for transfer goal and the motivating value they possess. In some cases, the concept would be created by combining the positive aspects from each of the concepts generated during the convergence stage, allowing it to incorporate the best elements from each of the initial ideas.

The ingredients of the game concept design stage are discussed in Appendix A. For each concept idea generated during the divergence stage, the designer might wish to define the main gameplay loop, a loop which represents the main actions of the player, the feedback they receive from their actions as well as the rules which govern them [64]. The designer might also specify which game elements (e.g. leader-boards, virtual rewards) or mechanics (achievement, collaboration competition) they wish to include in the game to make it appealing to the players (such as in [59]). If narrative elements are used, a description of the storyline or game metaphor could be provided. Narrative elements are useful for instance, in games designed to provoke awareness about specific issues or to persuade users to change their attitudes and beliefs by allowing them to assume a different role and see things from a different perspective. An example of this is a game designed to promote awareness about immigration by allowing users to play as a foreign student or asylum seeker [50]. Finally, designers could specify the key problem space which the concept tries to solve. In education games such as one aiming to teach Math for instance, it would be useful to specify which specific learning points or topics (such as Geometry) players would need to learn from the game for it to be successful [65].

To help formulate and evaluate the different game concepts, designers could carry out cocreative design sessions and evaluation sessions with stakeholders and subject matter experts. This can also be done to help expand the scope of existing ideas and ensure that the devised concepts remain relevant and applicable. During these sessions, various tools have been used in the game design industry to present the concepts to the stakeholders for evaluation and help stimulate in-depth discussion. For instance, talking images could be used as a simple way to represent different concepts by placing details of each concept on a large-size poster, allowing them to be easily compared with each other. Another approach called Gameplay Tinder has also been used to help stakeholders evaluate and discuss possible game elements or mechanics which could be applied to the concept. In this approach, the participants are provided with an explanation of different game elements and would either need to put them in a "Yes" or "No" pile and then justify their choices.

To help better convey the game concepts to the stakeholders, storyboards could be drawn. This involves producing a narrative of players as they go through the game and briefly describing their gameplay experience. The strength of a storyboard is that it communicates the user's interaction with the game from a user-centered perspective, rather than a technology-centered perspective. In a similar manner, mood boards could be constructed and used to investigate preferred artistic styles. Finally, to provide more structure when conceptualizing the persuasive game, a number of theoretical models and frameworks could be used (such as the MDA framework [25] or Deterring's lens of intrinsic skill atom [66]).

\subsubsection{Dish 3.2 Iterative Game Design and Development}

After the main concept has been decided, an iterative design and development approach is often applied to transform the concept into prototypes and the prototypes into the final persuasive game. Iterative design refers to how the game is designed and tested in iterations, with each new iteration incorporating feedback and insights from the prior round of testing, resulting in a gradual refinement of the designed game (see [67]). Generally, the ideas will evolve from broad overall concepts to a more specific description of functionality. If the designers adopt an agile approach towards game design and development, these functions will end up in the backlog (a prioritised list of all functionalities) or as user stories (a description of what the user can do) [63]. At this stage, the designers could also focus on designing and evaluating the components of the persuasive game, such as the proposed game play experience, which would evolve with each round of iterative testing. After sufficient iterations, the persuasive game would have incorporated all the necessary functions and be ready for usage with the clients.

The list of ingredients for this step is shown in Appendix A. Designers could focus on designing and testing the user interface which could be particularly important to prevent usability problems. In addition, designers could also examine and test the user experience design of the game, by mapping the player's expected gameplay experiences and journey throughout the game. This approach is particularly useful when players would need to achieve multiple objectives to realize the transfer effect (such as in games where players must go through multiple learning objectives to acquire new skills) or when a strong narrative element is required to guide player interactions. 
Finally, they could design and test the aesthetic elements and themes within the game, to determine which styles or themes (flat, futuristic, ancient etc.) would be preferable.

Various methods could be used at this step of game design. At the early stages of prototyping the concepts, simple prototypes such as a paper prototype could be used as a low-cost method of testing the game with the end user. At the later stages, more interactive prototypes could be created. Such prototypes would be particularly useful for testing early the interaction design of the game. For instance, in one game design project, the creators found that building an interactive prototype using the wizard-of-oz approach (where the designer manually manipulated the game to respond to user actions) helped saved time as they did not have to develop complex computer algorithms to test their ideas [68]. Later in the iterative cycle, a minimum viable product, in the case of persuasive games, a playable version of the game which contains only the essential parts required for gameplay, could be developed and used for a more thorough examination of the gameplay experience. Regardless of their level of fidelity, prototypes serve a useful role in formative evaluation and serve a generative role by helping designers reflect on their ideas [69].

When designers wish to examine specific aspects of the game, they can also carry out specific testing sessions, such as usability testing to identify and fix potential problems related to the interaction design of the game. Screen flow diagrams, which are mock-ups of different screens linked as a diagram could be created to show the relationships between different aspects of the game and would be particularly useful in testing interaction design. Gameplay testing could also be carried out to examine issues related to the perceived gameplay experience of users such as whether the game was too easy or difficult. To help evaluate the aesthetics of the game, concept art could be drawn and shown to the targeted audience. If the effect of a specific element would need to be examined, designers could also carry out A/B testing. This involves creating two versions of the game, one with a certain element which they want to examine and the other without the element to compare the results. As an example, A/B testing could be used to examine the effect of aesthetic elements such as music and animations on player retention [70].

\subsection{Dish 4: Evaluation of effects}

When the persuasive game has been designed and a playable version has been created for the user, the main question still remains: Is the persuasive game actually effective? In contrast to common expectations, the results of evaluative studies rarely provide a simple yes or no answer, but often provide margins of likelihood varying from very unlikely to an almost certainty. There are three types of values that an evaluation of persuasive games can aim to increase: a value at a knowledge level ("What can be learnt on how to design more effective persuasive games?"), at a user-effect level ("Did the game succeed in achieving the transfer-effect?"), and at a commercial level ("How does the game perform in the commercial market?").

The relevance of gathering empirical evidence to increase knowledge value seems to be uncontested. The statement that games are fun to play can be validated by letting a group of people play games and then observe and question them to see if they are indeed having fun. The resulting knowledge, that games are fun to play, might subsequently be developed further into research on the effective components of games. For instance, further evaluation tests could be carried out to understand more about how effective certain game mechanics and game design strategies are in different contexts (for example, to determine if a game design strategy based on competition would generally be useful in persuading young users to achieve physical exercise-based healthcare aims). Secondly, evaluation could offer value for the user. The user, varying from individuals to organizations to societies, can base their choice to use a persuasive game on the evidence of the evaluated effects. For instance, if evidence is available that playing a specific serious game will prolong your life for five years, users might be more inclined to invest personal effort in the game. Finally, the evaluation can have a commercial value since evaluation data can convince customers to purchase the game.

The ingredients of this dish are as follows. Most likely, the designer would be interested in examining any changes to user behavior that could indicate whether the transfer effect was achieved. For instance, in a persuasive game designed to improve life skills for children with ADHD, players could be examined to see if the essential life skills (social skills etc.) improved after playing the game [71]. In-game behavior such as play duration or in-game performance might also be useful in evaluating the effect of the game, if the transfer effect is expected to be realized within the game. In addition, the designer might be interested in examining the gameplay experience of the users. This includes examining their level of enjoyment and engagement with the game. In some cases, the games might even be considered effective, if they show similar levels of improvements in 
behavioral change as prior none game approaches, but provide a more enjoyable experience. In commercial game projects, when determining the marketability of the game to end-users, user acceptance might also be evaluated.

A variety of methods can be used in the evaluation of persuasive games. Often referred to as the "gold standard" approach to evaluating treatments in healthcare, Randomized Control Trials (RCTs)may be applied to evaluate the effects of persuasive games, particularly in games developed for the healthcare domain (such as [71]). RCTs typically involve systematically comparing the before and after effects of a population group which has gone through the persuasive game "intervention" in comparison to a baseline or placebo treatment approach. However, this method is often costly in time and effort (See [20] for a discussion). Alternatively, experimental studies could be carried out. This could be within subject studies where each participant is asked to evaluate different conditions (such as the persuasive game and a specifically designed placebo-like game or the persuasive game and the original none-game system (i.e. an existing treatment (for games designed in the healthcare domain) or the original learning approach (for games designed in the educational domain)). Another type of experimental studies employ a between subject design where each group of participants evaluates only one of several conditions. Less intensive methods, such as $\mathbf{N}=\mathbf{1}$ trials, which involve only one user, could be used to help establish an indication of the causal effect of the developed persuasive game. Apart from this, as a more informal way to gather feedback about the transfer effect of the persuasive game, designers could also collect anecdotes and testimonials from current users. In commercial settings, this could be particularly useful as anecdotes could be used to effectively communicate personal product experiences to other users. The utensils which designers could use to evaluate the persuasive game are shown in Appendix A.

\subsection{Case study example}

To give an example of how the dishes, utensils and ingredients could be used to formulate the design approach, we present a case study of a graduation persuasive game design project in collaboration with the Sophia Children's Hospital in Rotterdam. The persuasive game which is discussed as the case study (named Blaasweerspel, a combination of the Dutch words for 'fireman'/ 'brandweer', 'breathe again/ 'blaas weer' and 'game'/ 'spel') was aimed at helping train young children with cystic fibrosis to carry out flow-volume tests (See Figure 2). Cystic Fibrosis is a rare genetic disorder which causes damage to the lungs and other organs as the mucus inside these organs become increasingly viscous which reduces their performance. An overall summary of the PGD meal (dishes, ingredients and utensils) of the Blaasweerspel game is shown in Appendix B.

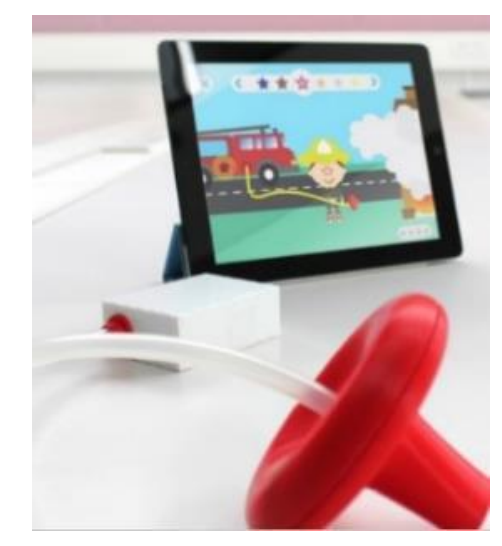

Figure 2: The Blaasweerspel game

\subsubsection{Dish 1: Defining the Transfer effect}

At the initial stage of the project, the designer felt that it was essential to understand more about the treatment and care of patients with Cystic Fibrosis to determine which transfer effect would have the best impact. The utensils carry out an initial expert discussion session and investigate scientific literature related to Cystic Fibrosis were used to help determine the transfer effect. The results showed that young children often have difficulty in performing such tests at the onset. However, if children are better prepared and trained, the reliability of the tests is expected to increase. More specifically, the hospital staff felt that it would be beneficial if there were a system which 
children could use at home to help train and familiarize them for the tests. Based on this, the designer felt that the first desired transfer effect in this case study should be to increase willingness for children to use the medical equipment in the flow-volume test at the children hospital. For this transfer effect, the ingredient effect type consists of trying to encourage attitudinal change so that the children become more accepting towards the flow-volume tests. For this type of change to occur, it would be necessary to alter existing behaviors and the optimal point of impact should occur shortly after gameplay as the children are expected to visit the hospital to carry out the actual tests one week after being given the game.

In addition, it was discovered that some of the children were afraid of the tests, due to their unfamiliarity with the specialized equipment used which caused them to be uncooperative. As such, for the second desired transfer effect, it would be beneficial to train children to become more familiar of the breathing techniques used in flow-volume test procedure. In this case, the ingredient effect type was to improve performance of the breathing tasks. To do so, it would be necessary to encourage children to form a new behavior of training regularly at home. Therefore, the point of impact is expected to occur during and shortly after gameplay. The domain of both transfer effects would be in the healthcare domain. Appendix B provides more details about the ingredients and utensils in this dish.

\subsubsection{Dish 2: Investigating the user's real world}

As the transfer effect which the game aims to achieved relied significantly on the real-world context of Cystic Fibrosis care as well as the interactions with the flow-volume tests, the designer judged that it would be necessary to learn more about the experiences of children with the tests and with Cystic Fibrosis care at the hospital. In particular, it was essential to investigate the ingredients Real world context, Attitudes towards the transfer effect and Game world preferences. As such, the utensils Observations were used to observe children as they carried out the flow volume tests and Context-mapping based generative interviews were carried out to gather latent knowledge about how children perceived and experienced the flow-volume tests. To learn more about the game world preferences, the observations also focused on the interaction of children with existing games that were used as part of the flow-volume tests at the hospital. This was supplemented by an analysis of various games popular for children of that age. In addition, interviews with specialist were carried out to learn more about Cystic Fibrosis and young children.

Overall, the results yielded various insight such as how children initially had difficulty with the flow-volume test as they had limited awareness/control over their breathing (Real world Context) and the potential value of incorporating a logical narrative storyline (Game world preferences). These results led to design recommendations such as how the game should naturally lead to the right breathing technique and should fit with the imaginative magical world of young children. Based on these results, the designer created Personas to better visualize the users for future design work.

\subsubsection{Dish 3: Persuasive game design}

To help generate ideas at the initial stage of concept design (Dish 3.1), the designer chose to use the utensil Carry out design sessions. This includes a creative session with students to come up with game ideas and a tinkering session to investigate different types of breathing toys. Overall, three concept ideas were generated (such as the magic whistle game which the main game loop involved children being challenged to imitate the sound a blowing train whistle to make the train move to next station and the narrative metaphor of "blowing a whistle to drive the train" was used to represent the breathing interaction). In each case, simple interactive prototypes were also built to test the technological feasibility of the concept ideas. These ideas were then discussed in an evaluative session with experts from the hospital and their feedback was used as input to help in the selection of the main concept idea based on a list of requirements generated from findings in dish 2 . The main concept was formulated by combining positive attributes from two initially proposed concept ideas.

Afterwards, the concept was refined into the final version of the persuasive game through iterative design. Throughout this procedure, the utensils "create an interactive prototype" was used. In addition, various testing sessions were carried out which contained elements of "gameplay testing" and "usability testing". Overall, the ingredients of the game, namely the user interface design, the user experience design and the aesthetics design evolved based on the findings from the testing sessions carried out in each iteration. In the first iteration, the whistle game concept was developed into an interactive prototype and tested with fellow students, children, parents and experts at the hospital. The results suggested the importance of sound as feedback and the need to include 
multiple game levels to simulate all the necessary breathing maneuvers. Therefore, in the next iteration, four different "game levels" representing the different breathing maneuvers that were necessary were created and the narrative of a fireman was adopted. Afterwards, another interactive prototype based on this idea was developed and tested with several children and their parents. The findings, such as the importance of gameplay balancing for children with different abilities, were applied to the third iteration and this led to the final design of the persuasive game. Overall, the final design consists of a digital tablet game where players assume the role of a fireman and must carry out a series of actions to put out the fire in the game by breathing and blowing on the breathing apparatus attached to the tablet. The designer chose to emphasize on game elements such as challenge and completion (progress to various level in the game) as playtesting sessions with prototypes in earlier iterations suggest that such mechanics could be effective in engaging players. Player breathing actions on the apparatus were linked to the in-game actions of the fireman in the game and were designed to fit with the overall narrative (player breaths in deeply= fireman fills in the water truck). A total of six game scenarios (game levels) were available, representing the different breathing maneuvers which is needed for the flow-volume test. A more detailed description of the ingredients and utensils of the final game design is found in Appendix B.

\subsubsection{Dish 4: Evaluation}

Due to limitations in time and resources, the designer felt it was not feasible to carry out a full medical evaluation of the game using a controlled experiment study. Such studies generally require the prolonged collaboration of a large number of specialized participants as well as additional medical expertise, equipment and facilities which the designer felt was beyond the scope and resources of the project. However, the designer felt that it would still be interesting to investigate if the game has potential to help achieve the transfer effects (increase willingness to use the equipment and become more familiar of the breathing techniques etc.) and whether it would create an enjoyable enough experience. Therefore, it was decided to investigate mainly the ingredients Gameplay Experience (Enjoyment, Challenge, Ease of use) and potential Changes to user behavior (breathing technique and willingness to engage with the breathing apparatus) by carrying out a small feasibility study (utensil). Overall, the results showed that children seem to enjoy the game and were enthusiastic. Players generally exhibited the correct technique of breathing out hard and breathing out long after playing the game, though some players did not yet show the correct technique in other breathing maneuvers (such as breathing in deep) after playing the game only once. In addition, the game seems to be successful in helping familiarizing children with the breathing apparatus and children all voluntarily used the mouthpiece. More details about the feasibility study could be found in appendix B.

\section{Conclusion}

This paper has discussed in detail the Persuasive Game Design method, a non-directive approach for designing persuasive games. Overall, the method presented in this paper provides several contributions to the existing practice and research of persuasive game design. While prior design methods in this domain tend either to be theoretical in nature or focus on a specific area within the persuasive game design process (behavioral change design etc.), the presented PGD approach covers the complete process of game design, combining theoretical knowledge from fields such as game design, product design and psychology with practical game development knowledge from the serious games industry to create an integrative approach for game design. In addition, the PGD method is unique in that rather than being presented as a directive game design approach for a specific application domain (learning, healthcare etc.), the method adopted a more generalized "cook-book" metaphor. This was done to provide more flexibility and help designers cope with the practical constraints encountered in persuasive game design. In this approach, designers are presented with various tools and knowledge which they could use to address the various questions encountered in each step of the persuasive game design process, helping them develop games that are effective in their desired context. Finally, a case study is presented to illustrating how the PGD method could be put into practice.

When using the PGD method, designers would craft a "meal" (a metaphor for the overall design approach which they plan to use to design their game) by selecting what "dishes" (a metaphor for the various steps in game design) should be cooked in that meal. They would then determine how these dishes should be cooked based on the task at hand, their expertise and available resource. The 
PGD meal generally consists of four dishes, Defining the desired transfer effect, Investigating the user's world, Game Design and Evaluation of effects. To determine how each dish should be cooked, the designer would select which ingredients (important elements to take account of in each design stage) should be included and what utensils (design tools) can be used. A comprehensive list of the ingredients and utensils are highlighted in this paper and a detailed description of each are provided in Appendix A.

A limitation in the PGD method is that the method focuses specifically on the role of the designer. In digital game design projects in particular, the design of the game is usually carried out in conjunction with the technical development and feedback from developers is often required when selecting which ingredient or utensil to use (particularly during dish 3 , the game design stage). In addition, by covering the complete design process of persuasive game design, it was only possible to provide a general overview of the available methods and not a detailed discussion for each one. Future work could be done to extend the dishes, ingredients and utensils in this model. In particular, the method could be further customized to fit with a specific context in persuasive game design (for instance, by purposely investigating and compiling a recipe of which dishes, ingredients and utensils work well in designing games for a context such as healthcare). In addition, although feedback from experienced game designers was obtained to formulate and refine the proposed method, future studies would need to be carried out to provide further in-depth validation of the PGD method. In particular to evaluate the development process and end product of games created using this approach, especially in a diverse context (for example, in academic research and student projects or in commercial game projects). Moreover, as discussed in section 2.2, additional work would need to be carried out to understand more about the mechanisms (i.e. how various game elements influence user experience and behavior) and validation of persuasive games (i.e. how to best assess the effect of such games) to further advance the research knowledge in this field. Finally, there still remains an open issue with regards to ethics in persuasive games and technology. For example, researchers in persuasive design have discussed issues related to the moral legitimacy of game systems which influence user behavior, the prior disclosure of motivation and the need for transparency and issues related to privacy [72] [73]. There is a moral risk when such games work to "change" the behavior of users without critical reflection from the users themselves.

It is expected that the proposed PGD method will be valuable to those designing persuasive games, both in the academic and industrial context. For game design practitioners, this method could be useful both to highlight the available tools and techniques in each stage of game design and as a "check-list" for designers to use in their existing practice. In the academic context, this method contributes knowledge to the persuasive game design domain, by providing a non-directive approach to game design based on a theoretical persuasive game design model. Overall, this paper seeks to advance the knowledge in the game design field by converting and combining existing theories in both the persuasive design literature (determining a transfer effect or analyzing user context etc.) and the game design literature (the conceptualization and development of the game etc.) into a practical and structured game design approach. In addition, the extendibility of this approach could make it particularly useful for education and learning, as users could customize the ingredients, utensils and dishes in this method to focus on a specific area of persuasive game design based on their discipline. In short, we, as a collaboration between game researchers and game design practitioners, hope that the proposed method could be useful in providing relevant information to the game designer (by providing a concise recipe print to hang on the wall, highlighting the available tools and techniques, providing inspiration and a check-list through the ingredients etc.), to researchers (by increasing understanding of the game design process and providing inspiration for research topics within game design) as well as to teachers and students (as a helpful method to teach and learn persuasive games design).

\section{Acknowledgement}

This paper was written as part of the Next Level Project which was funded by the NWO (Netherlands Organization for Scientific Research). We would like to thank the game design practitioners who gave valuable feedback for the development of the PGD method proposed in this paper. In addition, we would like to thank Maarten den Breeijen, Lye Goto of the TU Delft and Sandra Lever of the EURMC Sofia Children's Hospital for the case study discussed in this paper. 


\section{References}

[1] Visch V. T., Vegt N. J. H., Anderiesen H. and Van der Kooij K., "Persuasive Game Design: A model and its definitions.," in Paper presented at the CHI 2013: Workshop Designing Gamification: Creating Gameful and Playful Experiences, Paris, France., 2013.

[2] Green M., Brock R. and Kaufman G., "Understanding media enjoyment: The role of transportation into narrative worlds.," Communication Theory, vol. 14, no. 4, pp. 311-327, 2004. https://doi.org/10.1111/j.1468-2885.2004.tb00317.x

[3] Schell J., The Art of Game Design: A book of lenses., CRC Press., 2004.

[4] Deterding S., "The Lens of Intrinsic Skill Atoms: A Method for Gameful Design," HumanComputer Interaction, p. 294-335, 2015. https://doi.org/10.1080/07370024.2014.993471

[5] Woolrych A., Hornbæk K., . E. Frøkjær and G. Cockton, "Ingredients and meals rather than recipes: A proposal for research that does not treat usability evaluation methods as indivisible wholes.," International Journal of Human-Computer Interaction, pp. 940-970, 2011. https://doi.org/10.1080/10447318.2011.555314

[6] Strong W. and et al., "Evidence based physical activity for school-age youth.," The Journal of Pediatrics, pp. 732-737, 2005. https://doi.org/10.1016/j.jpeds.2005.01.055

[7] Feng J., . Spence I. and Pratt J., "Playing an action video game reduces gender differences in spatial cognition, 850-855.," Psychological science, 18(10), pp. 850-855, 2007. https://doi.org/10.1111/j.1467-9280.2007.01990.x

[8] Johnson D. R., "Transportation into a story increases empathy, prosocial behavior, and perceptual bias toward fearful expressions.," Personality and Individual Differences, 52(2), pp. 150-155, 2012. https://doi.org/10.1016/j.paid.2011.10.005

[9] Appel M. and Richter T., "Persuasive effects of fictional narratives increase over time.," Media Psychology, vol. 10, no. 1, pp. 113-134, 2007.

[10] Anderson A. C., Shibuya A., Nobuko I., Swing L. . E., Bushman B. J., Sakamoto A., Rothstein H. R. and Saleem M., "Violent video game effects on aggression, empathy, and prosocial behavior in Eastern and Western countries: A meta-analytic review.," Psychological Bulletin, Vol 136(2), , pp. 151-173, 2010. https://doi.org/10.1037/a0018251

[11] Abt C. C., Serious games, New York.: University Press of America, 1970.

[12] Bogost I., Persuasive games: The expressive power of videogames, Mit Press., 2007.

[13] Trépanier-Jobin G., "Differentiating Serious, Persuasive, and Expressive Games.," Kinephanos, vol. 6, pp. 107-128., 2016.

[14] Sicart M., "Against procedurality," Game studies, vol. 11, no. 3, p. 209, 2011.

[15] de la Hera C.-P. T., "A Conceptual Model for the Study of Persuasive Games," in DiGRA Conference 2013, 2013.

[16] Chen Y., Bodicherla D., Scott B. and Whittinghill D., "Meltdown: A Serious Game for Environmental Awareness on Climate Change.," in roceedings of E-Learn: World Conference on E-Learning in Corporate, Government, Healthcare, and Higher Education, Chesapeake, VA, Association for the Advancement of Computing in Education (AACE), 2014, pp. 388-394.

[17] Lin J. J., Mamykina L., Lindtner S., Delajoux G. and Strub H. B., "Fish'n'Steps: Encouraging physical activity with an interactive computer game," in UbiComp 2006: Ubiquitous Computing, Berlin, 2006.

[18] Adkins S., "The 2014-2019 Global Edugame Market.," in Serious Play Conference, 2015. 
[19] DeSmet A., Van Ryckeghem D., Compernolle S., Baranowski T., Thompson D., Crombez G., Poels K., Van Lippevelde W., Bastiaensens S., Van Cleemput K., Vandebosch H. and De Bourdeaudhuija I., "A meta-analysis of serious digital games for healthy lifestyle promotion," Preventive medicine, 69, pp. 95-107, 2014. https://doi.org/10.1016/j.ypmed.2014.08.026

[20] van der Kooij K., Hoogendoorn E., Spijkerman R. and Visch V., "Validation of Serious Games," International Journal of Serious Games, 2(3), 2015. https://doi.org/10.17083/ijsg.v2i3.75

[21] Montola M., Nummenmaa T., Lucero A. and Boberg M., " Applying game achievement systems to enhance user experience in a photo sharing service.," in Proceedings of the 13th International MindTrek Conference: Everyday Life in the Ubiquitous Era, 2009. https://doi.org/10.1145/1621841.1621859

[22] Richter G., Raban D. R. and Rafaeli S., "Studying Gamification: The Effect of Rewards and Incentives on Motivation," in Gamification in education and business, Springer International Publishing, 2015, pp. 21-46.

[23] Huizinga J., Homo ludens: A study of the play-element in our culture, Routledge \& Kegan Paul, 1949.

[24] Caillois R., Man,Play and Games, Urbana and Chicago: University of illinos Press, 1961.

[25] Hunicke R., LeBlanc M. and Zubek R., "MDA: A formal approach to game design and game research," in In Proceedings of the AAAI Workshop on Challenges in Game AI (Vol. 4), 2004.

[26] Juul J., Half-real: Video games between real rules and fictional worlds, Cambridge Massachusetts: MIT press, 2011.

[27] Sicart M., " Defining game mechanics," Game Studies, vol. 8, no. 2, pp. 1-14, 2008.

[28] Järvinen A., Games without frontiers: Theories and methods for game studies and design, Tampere University Press, 2008.

[29] Salen K. and Zimmerman E., Rules of play: Game design fundamentals, Cambridge, Massachusetts: MIT press, 2004.

[30] Rollings A. and Adams E., Andrew Rollings and Ernest Adams on game design., New Riders, 2003.

[31] Koster R., Theory of fun for game design., O'Reilly Media, Inc, 2013.

[32] Darnton A., "Reference report: an overview of behaviour change models and their uses," Government Social Research Unit, 2008.

[33] Fishbein M. and Ajzen I., Predicting and changing behavior: The reasoned action approach, New York: Psychology Press., 2010.

[34] Schwarzer R., "Modeling health behavior change: how to predict ad modify the adoption and maintenance of health behaviors.," Applied Psychology, 57(1), pp. 1-29, 2008. https://doi.org/10.1111/j.1464-0597.2007.00325.x

[35] Niedderer K. and et al., "Joining forces: investigating the influence of design for behavior change on sustainable innovation," in Norddesign, Espoo, Finland/ Melbourne, Australia, 2014.

[36] Tromp N., Hekkert P. and Verbeek P., "Design for socially responsible behavior: A classification of influence based on intended user experience.," Design Issues: history/theory/criticism, 27(3), pp. 3-19, 2011.

[37] Fogg B. J., "A behavior model for persuasive design," in Proceedings of the 4th international Conference on Persuasive Technology, ACM, 2009a. 
[38] Fogg B. J., "Creating persuasive technologies: an eight-step design process," in Persuasive, 2009b. https://doi.org/10.1145/1541948.1541999

[39] Lockton D., Harrison D. and Stanton N. A., "The Design with Intent Method: A design tool for influencing user behaviour," Applied ergonomics, vol. 41, no. 3, pp. 382-392, 2010. https://doi.org/10.1016/j.apergo.2009.09.001

[40] Starks K., "Cognitive behavioral game design: a unified model for designing serious games. Frontiers in psychology, 5.," Frontiers in psychology 5, 2014.

[41] Khaled R., Barr P., Biddle R., Fischer R. and Noble J., "Game design strategies for collectivist persuasion.," in Proceedings of the 2009 ACM SIGGRAPH Symposium on video games (pp. 31-38), ACM., 2009. https://doi.org/10.1145/1581073.1581078

[42] de la Hera T. C.-P. , "Persuasive Gaming: Identifying the different types of persuasion through games," International Journal of Serious Games, vol. 4, no. 1, pp. 31-39, 2017. http://dx.doi.org/10.17083/ijsg.v4i1.140

[43] Orji R., Mandryk R. L., Vassileva J. and Gerling K. M., "Tailoring persuasive health games to gamer type.," in In Proceedings of the SIGCHI Conference on Human Factors in Computing Systems (pp. 2467-2476), ACM., 2013. https://doi.org/10.1145/2470654.2481341

[44] Yusoff Z. and Kamsin A., "Game rhetoric: interaction design model of persuasive learning for serious games.," in International Conference on Learning and Collaboration Technologies , Springer, Cham., 2015. https://doi.org/10.1007/978-3-319-20609-7_60

[45] Arnab S., Lim T., Carvalho M. B., Bellotti F., de Freitas S., Louchart S., Suttie N., Berta R. and De Gloria A., "Mapping learning and game mechanics for serious games analysis," British Journal of Educational Technology, vol. 46, pp. 391-411, 2015. https://doi.org/10.1111/bjet.12113

[46] Roungas B., "A Model-driven Framework for Educational Game Design," International Journal of Serious Games, vol. 3, no. 3, pp. 19-37, 2016. https://doi.org/10.17083/ijsg.v3i3.126

[47] Knutz E., Markussen T., Visch V. T. and Desmet P. M. A., "Designing narrative games for a serious context," in In Out of control; proceedings of the 8th international conference on design and emotion, London (UK), 11-14 Sept. 2012, 2012.

[48] Tate, R., Haritatos, J and Cole S., "HopeLab's approach to Re-Mission.," 2009.

[49] Nicholson S., "A user-centered theoretical framework for meaningful gamification," Games+ Learning+ Society, 8(1)., 2012.

[50] Mitgutsch K. and Alvarado N., "Purposeful by design?: a serious game design assessment framework.," in Purposeful by design?: a serious game design assessment framework., ACM, 2012.

[51] Burke J. W., McNeill M. D. J., Charles D. K. M., Morrow P. J., Crosbie J. H. and McDonough S. M., "Optimising engagement for stroke rehabilitation using serious games.," The Visual Computer, vol. 25, no. 12, pp. 1085-1099, 2009. https://doi.org/10.1007/s00371009-0387-4

[52] Larsen L., Schou L., . H. Lund and H. Langberg, "The physical effect of exergames in healthy elderly - a systematic review.," Games for Health Journal, 2(4), pp. 205-212., 2013. https://doi.org/10.1089/g4h.2013.0036

[53] Kato P. M., Cole S. W., Bradlyn A. S. and Polloc B. H., "A video game improves behavioral outcomes in adolescents and young adults with cancer: a randomized trial," Pediatrics, 122(2), pp. e305-e317., 2008. https://doi.org/10.1542/peds.2007-3134

[54] Susi T., Johannesson M. and Backlund P., "Serious games: An overview," 2007.

[55] Anderiesen H., Sonneveld M., Visch V. and Goossen R., "Serious play for dementia: evaluation of the Active Cues Tovertafel,", Manuscript submitted for publication, 2015. 
[56] Visch V., Mulder I., Bos W. and Prins R., "The Travelling Rose: A Persuasive Game to Stimulate Walking Behaviour of Older Persons in Low SES Neighbourhoods," in Gamification: Concepts, Methodologies, Tools, and Applications, 2015. https://doi.org/10.4018/978-1-4666-8200-9.ch065

[57] Vegt N. J. and Visch V. T., "Social gaming rules: Changing people's behavior through games.," in CHI 2013: Gamejam Workshop, 27 April-2 May 2013. , Paris, France, 2013.

[58] Hassenzahl M., Experience Design: Technology for All the Right Reasons, Morgan and Claypool Publishers, 2010.

[59] Vegt N., Visch V., . H. de Ridder and A. Vermeeren, "Designing Gamification to Guide Competitive and Cooperative Behavior in Teamwork," in Gamification in Education and Business, Switzerland, Springer International Publishing, 2014, pp. 513-533.

[60] Prins P. J., Brink E. T., Dovis S., Ponsioen A., Geurts H. M., De Vries M. and Van Der Oord S., "'Braingame Brian": toward an executive function training program with game elements for children with ADHD and cognitive control problems. GAMES F," in GAMES FOR HEALTH: Research, Development, and Clinical Applications, 2013.

[61] Mubin O., Shahid S. and Al Mahmud A., "Walk 2 Win: towards designing a mobile game for elderly's social engagement," in In Proceedings of the 22nd British HCI Group Annual Conference on People and Computers: Culture, Creativity, Interaction, 2008.

[62] Lucero A. and Arrasvuori J., "PLEX Cards: a source of inspiration when designing for playfulness," in Proceedings of the 3rd International Conference on Fun and Games, 2010.

[63] Godoy A. and Barbosa E. F., "Game-scrum: An approach to agile game development.," in Proceedings of SBGames, 2010.

[64] Yannick F., Abdelkader G. and Nadia H., "A Gameplay Loops Formal Language," in The 17th International Conference on Computer Games, KY, USA, 2012.

[65] Álvarez-Rodríguez F. J., Barajas-Saa A. and Muñoz-Arteaga J., "Serious Game Design Process, Study Case: Sixth Grade Math," Creative Education, vol. 5, pp. 647-656, 2014.

[66] Deterding S., "The lens of intrinsic skill atoms: A method for gameful design," HumanComputer Interaction 30(3-4), pp. 294-335, 2015. https://doi.org/10.1080/07370024.2014.993471

[67] Ballagas R. and Walz S., "REXplorer: Using player-centered iterative design techniques for pervasive game development.," in Pervasive Gaming Applications, 2007.

[68] Höysniemi J., Hämäläinen P., and Turkki L., "Wizard of Oz prototyping of computer vision based action games for children.," in Interaction design and children: building a community, 2004.

[69] Lim Y. K., Stolterman E., and Tenenberg J., "The anatomy of prototypes: Prototypes as filters, prototypes as manifestations of design ideas. (TOCHI), 15(2), 7.," ACM Transactions on Computer-Human Interaction (TOCHI), vol. 15, no. 2, 2008.

[70] Andersen E., Liu Y. E., Snider R. and Szeto R., "Placing a value on aesthetics in online casual games.," in Proceedings of the SIGCHI Conference on Human Factors in Computing Systems ACM., 2011.

[71] Bul K. e. a., "Effects of "Plan-It Commander" on Behavioral Outcomes for Children with ADHD: A Randomized Controlled Trial.," Journal of Medical Internet Research, 2016. https://doi.org/10.2196/jmir.5173

[72] Berdichevsky D. and Neuenschwander E., "Toward an ethics of persuasive technology.," Communications of the ACM, vol. 42, no. 5, pp. 51-58, 1999. https://doi.org/10.1145/301353.301410 
[73] Kim T. W. and Werbach K., "More than just a game: ethical issues in gamification," Ethics and Information Technology, vol. 18, no. 2, pp. 157-173., 2016.

https://doi.org/10.1007/s10676-016-9401-5

\section{Appendix}

Appendix A: A summary of the ingredients and utensils for the PGD method 


\section{DISH 1: DEFINING THE TRANSFER EFFECT}
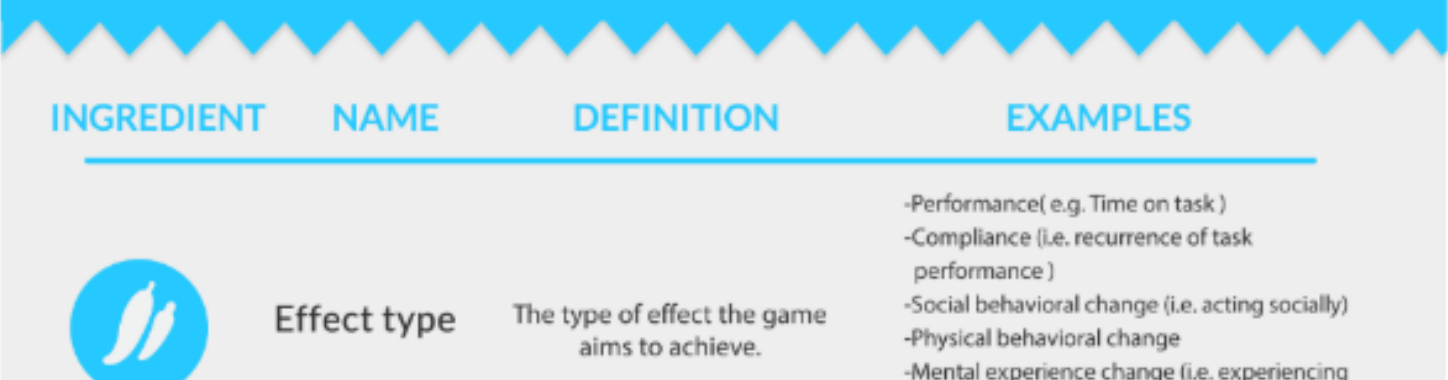

-Performance( e.g. Time on task )

-Compliance (i.e. recurrence of task

performance )

-Social behavioral change (i.e. acting socially)

-Physical behavioral change

-Mental experience change fi.e. experiencing

change in terms of social connectedness.

self-esteem, emotions, etc.)

-Attitudinal change (with respect to various

behaviors)

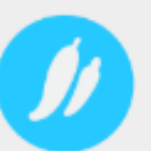

\section{Change type}
The type of change that is aimed for in relation to the existing pre-game

(real world) behavior.

\section{-Reinforce}

-Alter

-Forming/ creating$$
\text { (reas }
$$

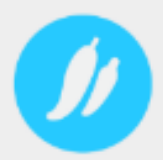

Point of impact

The period in which it is expected to achieve the aimed-for change.

-Effect is realized during gameplay -Effect is realized on a short term after gameplay (minutes/ hours/ days) -Effect is realized on a long term after gameplay (days/ weeks/ months/ years) after gameplay

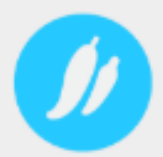

The application domain in
Domain the change takes place

Healthcare context (e.g. hospital, therapy) -Business (e.g. office, factory)

-Education [e.g. school, trainee programs) -Society (e.g. cities, neighbourhoods) -Personal life (e.g. family, individual users) 


\section{DISH 1: DEFINING THE TRANSFER EFFECT}

\section{$\wedge$ \\ UTENSILS \\ NAME \\ DEFINITION \\ CHARACTERISTICS}

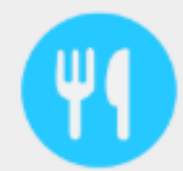

Carry out expert sessions
Carry out a meeting with designers and experts of the application domain to define preferred transfer effect.
-Allows the designer to gain an in-depth understanding of the domain.

-Probability expectations of aimed-for transfer effect will be discussed (e.g. isn't the aim too ambitious?)

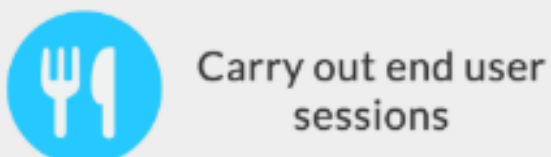

Carry out a meeting with the client or end user to investigate what is expected on the realization of transfer effect.
-Gives a first indication of motivation of end user for transfer effect.

-The means to realize the transfer effect are yet unknown.

\section{Carry out science sessions}

Carry out a meeting with scientists to check the feasibility of evaluating transfer effect.
-Helps formulate the methods used to evaluate the game later during the evaluation process (How and when do we know if we realized the transfer-effect? etc.)

-Might limit the area of the transfer effect
Informative. Provides a summary of the knowledge in the transfer effect domain. -Examples provided might not be applicable to the case study at hand

\section{Conduct rapid design sessions}

Conduct 2-3 days intensive rapid design sessions together with designers, stakeholders and clients.
Helps clients form a clearer image of what business objective is important to implement through gamification project

- Helps manage stakeholder expectations -Requires substantial collaboration in time and effort from the stakeholders

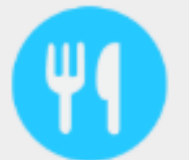

\section{Carry out best practices research}

Examine already existing interventions
-Helps to reveal some proven concepts -Working examples have often tackled lots of issues that can be translated to game play 


\section{DISH 2: INVESTIGATING THE USER'S WORLD}

\section{INGREDIENTS NAME}

\section{DEFINITION}

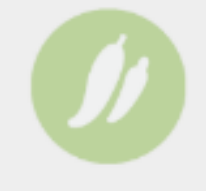

\section{Real world Context}

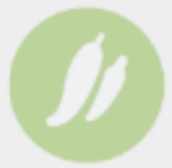

\section{Existing motivational affordances}

The users' current behaviour, experience and the context in which these occur.
-Context (physical, technical, social, work etc.)

-Activities (initiative for tasks, autonomy,

procedures, interruptions, rituals, hobbies, etc.) -User's skills

-Users' current experiences: anticipation, actual and memories of experiences.

-Characteristics of the transfer effect (effect type, change type, period and domain). Is it a transfer that is meaningful to the user? User needs (e.g., mastery, autonomy, sociality; these relate to what motivates users) -Values (these determine user considerations of what is worthwhile doing or getting engaged with)

-Beliefs (what are beliefs people have about issues related to the Persuasive game or the transfer effect; this may influence their attitude towards them, as well as their self-efficacy)

-Concerns (what are important issues in the user's life, that may influence their (emotional) reactions to the persuasive games?

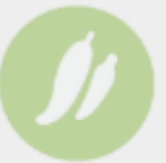

Attitude towards transfer effect
The characteristics of the users that play a role in making the transfer effect effective.
-Stable characteristics: personality traits, self-efficacy etc.

-Mutable characteristics: beliefs/previous experiences with, and skills needed in the transfer or for the intended behavior after transfer.

\section{Game World preferences}

The type of experiences users want games to offer and the game characteristics that appeal to the users.
-Preferred playful experiences (Challenge, Simulation etc.)

-Preferred aesthetics style (Cartoon, Realistic, Simplistic)

-Game Interaction style preferences: social/individual, undergo-passive/do-active, mental/bodily

-Preferred forms of play: constructive play, pretend play, physical play, social play, games with rules 


\section{DISH 2: INVESTIGATING THE USER'S WORLD}

\section{UTENSILS}

NAME

DEFINITION

CHARACTERISTICS

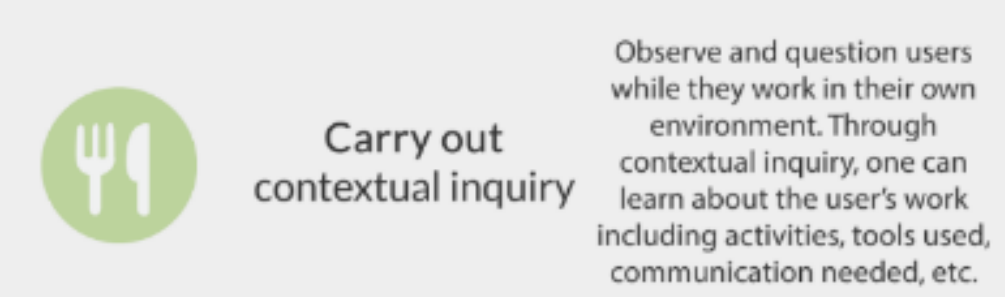

Observe and question users while they work in their own environment. Through

learn about the user's work communication needed, etc.

Use questionnaires to learn more about the stakeholders. Generally, questionnaires make use of tick boxes or scales for ease of answering and ease of data analysis.

Questions are often complemented with boxes for additional verbal information.

\section{Conduct a questionnaire study}

-Significant cost in time and effort, as one-on-one interviews need to be carried out to walk through the user's activities. -Requires specific expertise in interviewing, The interview needs to feel like a conversation about the user's work, while keeping focus on the topics of interest and remain flexible enough for unexpected findings.
Carry out a focus group meeting with application domain experts to learn about the users.
-Provides quantifiable answers to a specific context.

-Can be used to elicit a stance from participants before a focus group discussion or interview

-Questionnaires with standardized and validated constructs can be used to compare the current situation to other situations. However, using such constructs make it hard to de-contextualize the results.

-Tailor-made questionnaires can be created to explore a specific context, but requires proper research to ensure that questions are formulated properly and that the right questions are asked.

\section{Carry out focus groups with domain experts \\ (in)} .

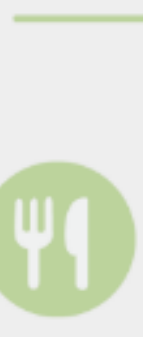

\section{Conduct observation sessions}

Observe users in their native context or as they interact with a prototype.

Observers may be present and record what they see by hand or through technology.

Observants may or may not be aware of the observations, and observers may or may not actively influence the scene being observed.
-Used to help provide an external view on the above mentioned ingredients that is backed up by scientific knowledge and/or experience from having been involved in many cases -Experts may be blased by the specific discipline they come from or their research paradigms 


\section{DISH 2: INVESTIGATING THE USER'S WORLD}

\section{UTENSILS}
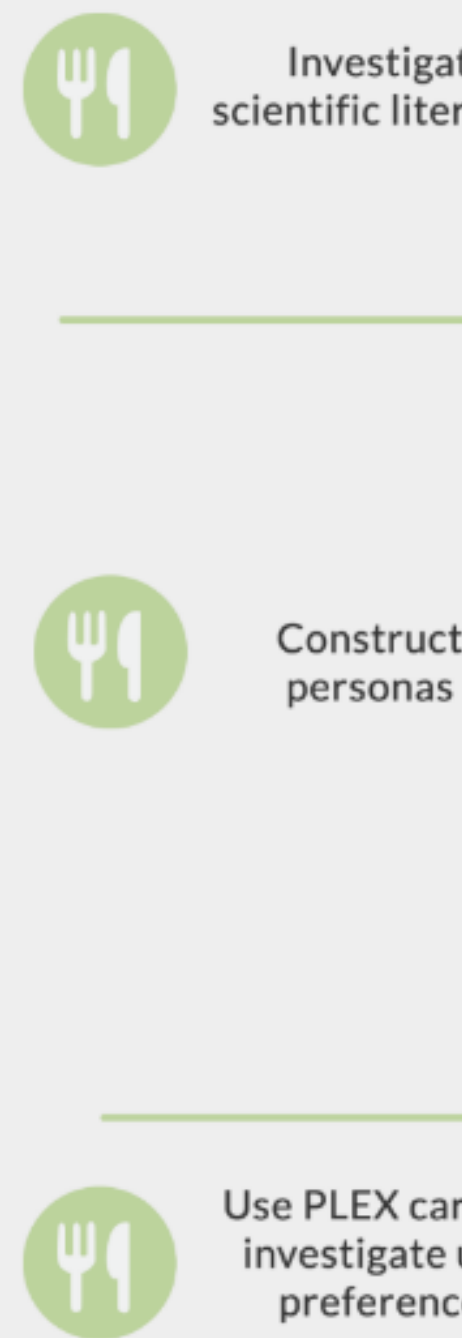

Investigate scientific literature to gain an insight into the potential users.

-Can provide an overview insight (e.g., across many disciplines, activities, etc.)

-Data has been compiled and gone through a level of analysis.

-Can provide first-hand data and opinions shared between users (e.g. in social media or on forums).

-Can be difficult to apply the findings to the current context.

-Provides the design and development team with an overview of what issues are important to users.

-Encourages them to constantly evaluate their design against these personas and minimizes

Construct personas of users. Personas are representations of fictitious users that includes a concise summary of characteristics of the user, their experience, goals and tasks, pain points, and environmental conditions. the tendency of designers and developer to self-impose preconceptions about the users. -Personas can be used in multiple stages of the design, such as during requirement gathering to visualize user needs for non-technical stakeholders or during development, to provide engineers with a context for their work.

-To avoid too narrow a focus, a small set of personas need to be created. To ensure validity, these must be crafted based on robust user research, which often requires considerable insight about different dimensions of user characteristics not available in market research.

\section{Use PLEX cards to investigate user preferences}

Use PLEX cards (A set of 22 playful experience cards) to investigate possible play experience preferences.
-Used to investigate user play preferences based on a structured set of play experiences. 


\section{DISH 3.1 : CONCEPT DESIGN}

\section{INGREDIENT \\ NAME

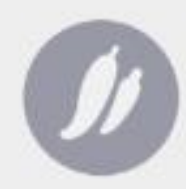

The main gameplay

The main interaction and loop feedback loop of the game.

- The main player actions and the feedback and reward the game (i.e. answer a question correctly and gain experience points and level up)

-The rules which drive the main player interaction

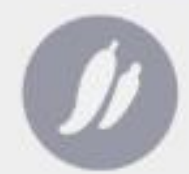

Game elements and mechanics

The potential game elements and mechanics which would appeal to the user's interest.
-Game mechanics: competition, collaboration, progression, etc.

-Game elements points, leaderboard, rewards, etc.

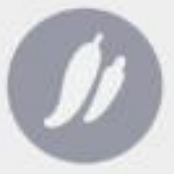

\section{Game metaphor/} Storyline
A description of the storyline and metaphor used in the concept
-Fictional player roles; (researcher, doctor, warrior)

- Metaphor for player actions: i.e. Progressing along a linear path as a metaphor for player progression

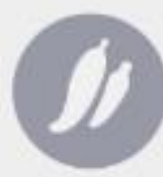

Concept problem space

NAME

Carry out rapid design Sessions
A design session limited in time but with all stakeholders available,
-The specific learning points which players need to learn from the game to drive user behaviour

-The specific behaviours which is intended from the game (walking a mile every day etc.)

\section{CHARACTERISTICS}
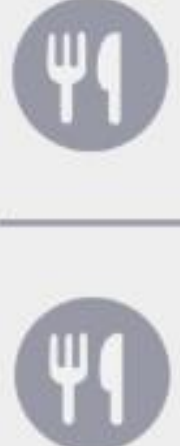

Carry out design and evaluative sessions with stakeholders: subject matter experts, end-users, business owners, product owner.
-Design team can start designing and consult SME's and business owners when needed -Limited time waste

-Effective alignment of all stakeholders 


\section{DISH 3.1 : CONCEPT DESIGN}

\begin{tabular}{|c|c|c|}
\hline UTENSILS & NAME & DEFINITION \\
\hline & $\begin{array}{l}\text { Use Deterding's } \\
\text { lens of intrinsic } \\
\text { skill atom to } \\
\text { formulate } \\
\text { gameplay }\end{array}$ & $\begin{array}{l}\text { A gameful design method } \\
\text { which identifies challenges } \\
\text { inherent in a user's pursuit } \\
\text { towards a goal and } \\
\text { restructures them into } \\
\text { motivating game experience }\end{array}$ \\
\hline
\end{tabular}

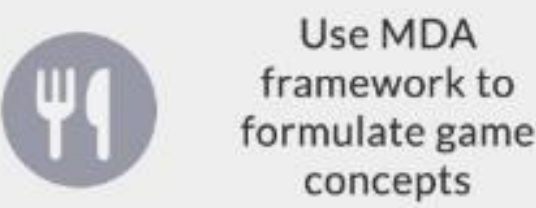

concepts
Used to analyse games based on three components:

Mechanics, Dynamics and Aesthetics.
- Provides a systematic way of viewing and analyzing the persuasive game from the serious activity's skill-based challenge components

-Focuses mainly on the element of challenge and gratifying the player's need for competence.

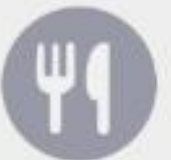

\section{Construct mood boards}

Create provisional sketches images, texts etc to evoke a style or concept.
Easy to comprehend

-Too simple for specific design

No clear boundaries between the

components

\section{(49) \\ Draw Storyboards}

Draw storyboards to illustrate the interaction between a person and the game in a narrative format.
-Used to align ideas on the look and feel -Used to visualise ideas for other stakeholders.
-Provides a more meaningful way to convey user experience and action (than through technical diagrams such as flowcharts) which helps visualize the gameplay experience -Does not require programming skills or artistic skills

-Not practical for detailed design or covering all user action cases.

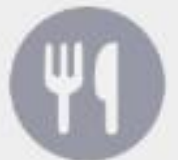

\section{Gameplay Tinder}

\section{Talking images}

Game concepts are explained on a large sized poster so clients can give feedback and compare different concepts
-Quick way to decide on which game mechanics or elements would be useful -Discussion could yield fruitful information on which game element or types of concept is preferable for participants 


\section{DISH 3.2 : GAME DESIGN}
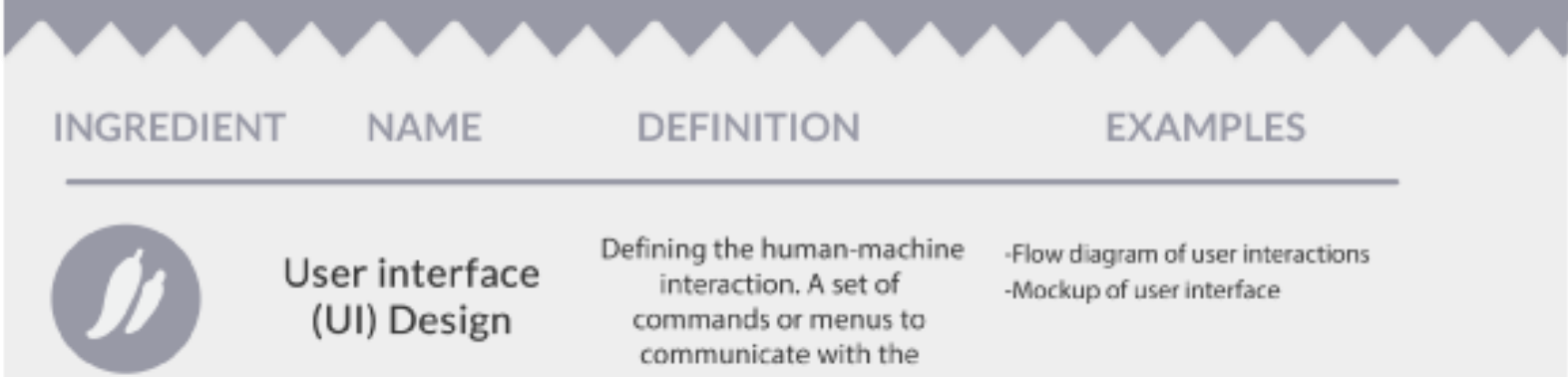

\section{User interface \\ (UI) Design}

Defining the human-machine interaction. A set of commands or menus to communicate with the program.
-Flow diagram of user interactions

-Mockup of user interface

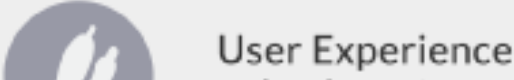 (UX) Design}

Defining the overall experience, in general or specific that a user has with the game.
-A map of the player's gamplay experience journey in phases such as discovery. onboarding, scaffolding(habit building). mastery climax and end play

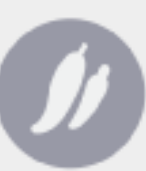

Aesthetics, theme design

Define the overall visual theme and appearance of the game
-Artistic style (flat style, futuristic, ancient) -Colour Schema

\section{Create Paper prototypes for testing}

Used to create a proof of concept for evaluative feedback with users, using as little resources as possible
-Good for defining the main gameplay loop -Clear focus on the goal to achieve allowing for increments later

-Oversimplifying the solution Need to redesign for the real thing

\section{(II) Create an \\ III Interactive prototype}

\section{Create an interactive} prototype of the game in which only the parts essential to the product are included
-Useful for early testing the interaction design of the game.

-Gain insight on the perception of players towards the overall game.

-Not able to examine gameplay experience in detail 


\section{DISH 3.2 : GAME DESIGN}

UTENSILS

NAME

DEFINITION

\section{CHARACTERISTICS}

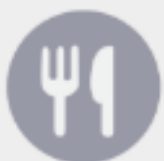

Carry out usability Testing

Carry out tests with users to

-Allows the designer to identify and fix any identify and diagnose usability problems or detemine the potential problems regarding the aspects overall level of usability related to the interaction design (game structure, ease of play etc.)

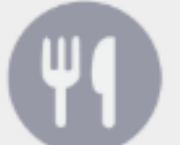

Carry out gameplay testing

Carry out tests with users to examine the gameplay experience

- Actual users or proxy users are asked to play the game or prototype of the game -Examine issues related to the gameplay (balance, level of challenge, difficulty etc.)

-Create a mock up representing different "screens" of the game and link them within a diagram to show the functions and features of the game.

-Useful in showing the relationships between different aspects of the game and in testing interaction design.

Gives a good overview of the features of the game used in the game

-Concept art sketches of the user interface

\section{Create sketches of the concept art used in the game \\ Create concept art}

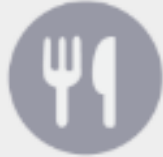

Create a playable version of the game in which only the parts essential to the product are included
-Useful for early testing of the core gameplay, provides a prototype which can be tested with users at a lower cost than a full product -Substantial cost needed to develop 


\section{DISH 4: EVALUATION OF EFFECTS}

\section{INGREDIENT}

NAME

DEFINITION

EXAMPLES

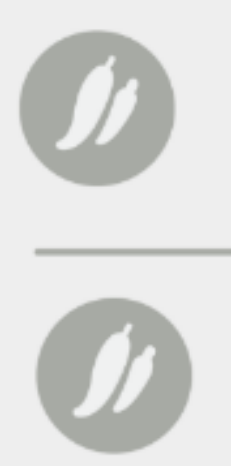

Gameplay
Experience

In-game

behaviour

Evaluate the changes in the behavior from their in-game actions.
-Enjoyment/Engagement

-Flow

-Challenge

-Immersion/ Presence

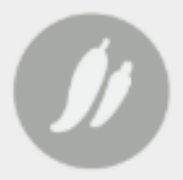

\section{Changes to user} behaviour
The effect of the game on the user. This effect can be related to changes in cognitive, behavioral, attitude or knowledge, at a specific gameplay period after the gameplay.
-Total play duration (minutes, hours) -In game objectives completed -In game performance

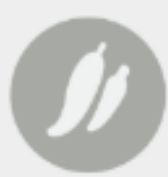

User acceptance

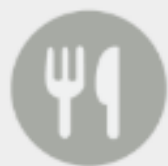

Carry out within Subject Study (WS) experiment
Testing to see if the gamification meets the needs and requirements of the stakeholders
- Behavioral outcome (Adherence) - Changes in attitude and beliefs - Psychological outcome (self-esteem etc.) - Cognitive outcomes (memory, spatial skills etc.)

- Changes in Knowledge and skills
-Main user acceptance (Actual users such as patients, employees, students etc) -Related stakeholder acceptance (Care staff, Teachers, managers etc.)

-Institutional acceptance (Healthcare facility, schools etc.)

\section{CHARACTERISTICS}

Using one group of participants who receives one or more conditions (games or game variants) and is tested before (A1) and during/after (A2, A3) gameplay. Typically $A 1 B A 2 C A 3$ in which $B$ and $C$ are game variants.
-You need only one group of participants that is representative for the target group. -Risk of carry over-and order-effects with ABACA structure (B might effect $C$ : like playing a zombie game might effect playing sims). To control for the order effect you can randomized the order of conditions for each participant. Controlling for carry-over effect is more difficult. You can insert breaks (e.g. one week) between the conditions or turn to a Between Subject Study set-up. -No individual bias: each participant is affected by all conditions. 


\section{DISH 4: EVALUATION OF EFFECTS}

\section{UTENSILS NAME DEFINITION CHARACTERISTICS}

Using two groups of participants to test the effect of the game. Both groups are measured before (A1) and after (A2) the game but only

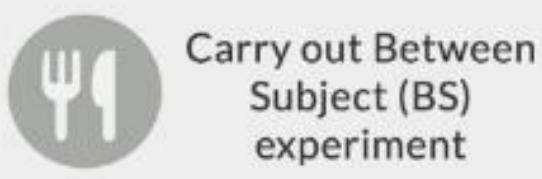
one group receives the target game $(\mathrm{B})$ and the other group functions as control group (C). The control group may play no games and receives treatment as usual (TAU) or specially designed placebo-like games. By comparing the measurements of both groups the effect of the target game can be acquired.

\section{- Since this study type compares the} measurements of two groups you need more participants than a WS set-up. Moreover, the two groups should be equally representative of the target group.

-Risk individual biases: not all participants receives all stimuli.

-No carry over effect.

-Often used to test only one condition instead of a series of conditions.

It is difficult to design a placebo game.

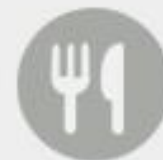

\section{Carry out a $\mathrm{n}=1$ trail}

Single case study

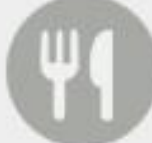




\section{DISH 4: EVALUATION OF EFFECTS}

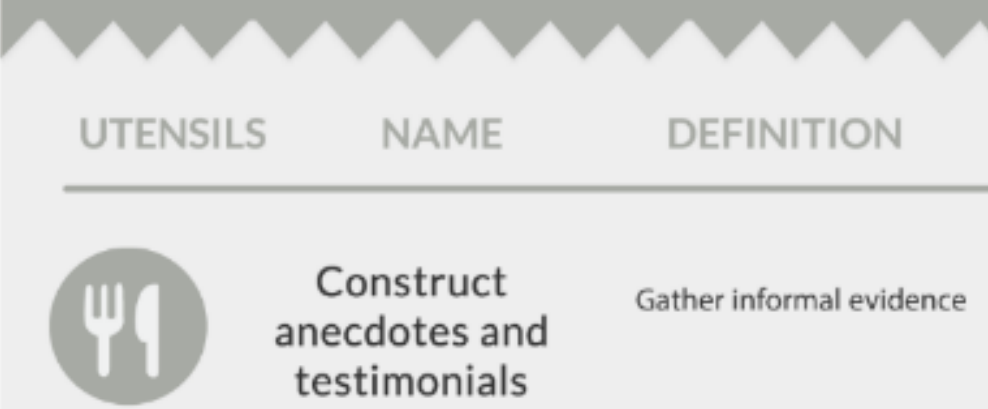

\section{CHARACTERISTICS}

-Cheap and fast but unreliable since the users may not be representative for the target group and strongly biased towards a positive outcome.

-Often the outcome variables are not included but based on expectation.

this might however serve as a first indication to decide on setting-up more formal studies. anecdotes can commercially be strong since they are easily communicated. 
Appendix B: The PGD meal (dishes, ingredients and utensils) of the Blaasweerspel game.

\begin{tabular}{|c|c|c|c|}
\hline Dish & & Ingredients & Utensils \\
\hline \multirow{4}{*}{ Dish 1} & Effect type & $\begin{array}{l}\text { - Attitudinal change (increase } \\
\text { willingness to use the flow-volume test } \\
\text { equipment) } \\
\text { - Performance (Improve the } \\
\text { performance when carrying out } \\
\text { breathing tasks for flow-volume test) } \\
\text { (breath length, depth etc)). }\end{array}$ & \multirow[t]{4}{*}{$\begin{array}{l}\text {-Carry out expert sessions } \\
\text {-Investigate scientific } \\
\text { literature }\end{array}$} \\
\hline & Change type & $\begin{array}{l}\text {-Alter existing behaviors (Instead of } \\
\text { being scared of the tests, become more } \\
\text { motivated) } \\
\text {-Encourage a new behavior of } \\
\text { practicing breathing techniques at home }\end{array}$ & \\
\hline & Point of Impact & $\begin{array}{l}\text {-Shortly after gameplay (encourage } \\
\text { them to be more accepting towards the } \\
\text { test which is carried out a week after } \\
\text { playing the game) } \\
\text { - During gameplay (the breathing } \\
\text { performance should improve as they } \\
\text { play the game) }\end{array}$ & \\
\hline & Domain & $\begin{array}{l}\text { Healthcare context (at a children's } \\
\text { hospital). It is therefore important to } \\
\text { consider carefully issues such as user } \\
\text { characteristics and hygiene etc. to avoid } \\
\text { creating a game which could have an } \\
\text { adverse effect on the clients. }\end{array}$ & \\
\hline \multirow{3}{*}{ Dish 2} & Real world context & $\begin{array}{l}\text {-User's current experiences (Children } \\
\text { encountered various difficulties with the } \\
\text { flow-volume tests for the first time as } \\
\text { they have limited awareness/control of } \\
\text { their breathing etc.) } \\
\text { - Context (The importance of parental } \\
\text { involvement/guidance during home } \\
\text { training etc.) }\end{array}$ & \multirow[t]{3}{*}{$\begin{array}{l}\text {-Conduct Observation } \\
\text { sessions } \\
\text {-Carry out context } \\
\text { mapping based generative } \\
\text { interviews } \\
\text {-Conduct interviews with } \\
\text { domain experts } \\
\text {-Construct Personas }\end{array}$} \\
\hline & $\begin{array}{l}\text { Attitudes towards } \\
\text { the transfer effect }\end{array}$ & $\begin{array}{l}\text { - The characteristics of the users } \\
\text { (physical, cognitive ability) which } \\
\text { influence the desired transfer effect. For } \\
\text { instance, children have limited linguistic } \\
\text { ability, concentration and lung capacity } \\
\text { at young age etc.) }\end{array}$ & \\
\hline & $\begin{array}{l}\text { Game world } \\
\text { Preferences }\end{array}$ & $\begin{array}{l}\text {-Preferred playful experience } \\
\text { (experiences involving narration is } \\
\text { promising due to the imagination of } \\
\text { children) } \\
\text {-Game interaction style preference } \\
\text { (Individual play is preferred) }\end{array}$ & \\
\hline \multirow[t]{2}{*}{ Dish 3} & $\begin{array}{l}\text { The main gameplay } \\
\text { loop }\end{array}$ & $\begin{array}{l}\text {-As the main game loop in each } \\
\text { scenario, players are challenged to carry } \\
\text { out an appropriate breathing action with } \\
\text { the appropriate force. Narrative based } \\
\text { visual and audio feedback is provided to } \\
\text { show player performance and game } \\
\text { progression. If they are successful, they } \\
\text { move to the next scenario. For instance, } \\
\text { players blow on the equipment to try to } \\
\text { help the fireman put out a fire. If they } \\
\text { are successful parts the water hits the } \\
\text { fire and it sizzles, if not the water from } \\
\text { the hose will fall short of the fire. }\end{array}$ & $\begin{array}{l}\text { (Dish 3.1) } \\
\text {-Carry out creative design } \\
\text { sessions } \\
\text {-Build interactive } \\
\text { prototypes } \\
\text {-Carry out evaluative } \\
\text { sessions } \\
\text { (Dish 3.2) } \\
\text {-Create interactive } \\
\text { prototypes }\end{array}$ \\
\hline & $\begin{array}{l}\text { Game elements and } \\
\text { mechanics }\end{array}$ & $\begin{array}{l}\text { Challenge, Completion (progression to } \\
\text { various levels in the game) }\end{array}$ & $\begin{array}{l}\text {-Carry out gameplay } \\
\text { testing } \\
\text {-Carry out usability testing }\end{array}$ \\
\hline
\end{tabular}




\begin{tabular}{|c|c|c|c|}
\hline & Game metaphor & $\begin{array}{l}\text { The narrative setting is of a fireman } \\
\text { trying to extinguish a fire. Player } \\
\text { breathing actions are a metaphor for the } \\
\text { in-game actions of the fireman,i.e. } \\
\text { breathing out long to blow away all the } \\
\text { smoke. In addition, wearing the nose } \\
\text { piece (which is a necessary part of the } \\
\text { breathing apparatus in the game) is } \\
\text { explained narratively as to protect } \\
\text { against smoke from the fire in the game. }\end{array}$ & \\
\hline & $\begin{array}{l}\text { Concept problem } \\
\text { space }\end{array}$ & $\begin{array}{l}\text { Six different breathing maneuvers } \\
\text { beneficial for the flow-volume tests } \\
\text { (breathing out hard, long etc.) }\end{array}$ & \\
\hline & $\begin{array}{l}\text { User interface } \\
\text { Design }\end{array}$ & $\begin{array}{l}\text { A simplistic user interface design was } \\
\text { adopted, one which young children } \\
\text { could use. The main UI element was a } \\
\text { progress bar interface which allowed } \\
\text { children change between the game and } \\
\text { see their progress. }\end{array}$ & \\
\hline & $\begin{array}{l}\text { User Experience } \\
\text { Design }\end{array}$ & $\begin{array}{l}\text { A linear gameplay is adopted. As part of } \\
\text { their journey, players are presented with } \\
\text { various narrative scenarios which } \\
\text { represent the beneficial breathing } \\
\text { maneuvers (First, by breathing out hard } \\
\text { to extinguish the fire and then breathing } \\
\text { out long to blow away the smoke etc.) }\end{array}$ & \\
\hline & Aesthetics Design & $\begin{array}{l}\text { To appeal to young children, a cartoon } \\
\text { like aesthetics style with bright colors } \\
\text { was adopted. }\end{array}$ & \\
\hline \multirow[b]{2}{*}{ Dish 4} & $\begin{array}{l}\text { Gameplay } \\
\text { Experience }\end{array}$ & $\begin{array}{l}\text { Enjoyment - Children seem to enjoy } \\
\text { the game and were enthusiastic to play } \\
\text { it. } \\
\text { Challenge - Acceptable level in buildup } \\
\text { of difficulty, though some game levels } \\
\text { were a bit difficult. } \\
\text { Ease of Use -The parents mentioned the } \\
\text { interface was easy to understand for } \\
\text { children, though some minor usability } \\
\text { issues were identified. }\end{array}$ & \multirow[t]{2}{*}{$\begin{array}{l}\text {-Carry out a feasibility } \\
\text { Study (by using } \\
\text { observations and semi- } \\
\text { structured interviews) }\end{array}$} \\
\hline & $\begin{array}{l}\text { Changes to user } \\
\text { behavior }\end{array}$ & $\begin{array}{l}\text { Obtained skills -During the game, } \\
\text { some children exhibited the correct } \\
\text { technique in breathing out hard and } \\
\text { breathing out long, though most did not } \\
\text { yet show the correct technique when } \\
\text { breathing in deep and when breathing } \\
\text { out hard and then long after playing } \\
\text { with the game only once. Sometimes } \\
\text { this required the parents to first help } \\
\text { explain and show how it could be done. } \\
\text { Attitude -Although some children were } \\
\text { a bit hesitant at the beginning, they all } \\
\text { voluntarily used the mouthpiece. The } \\
\text { game seems to be successful in helping } \\
\text { familiarizing children with the breathing } \\
\text { apparatus. }\end{array}$ & \\
\hline
\end{tabular}

